\title{
Critical Evaluation of Methods for Determining Total Organic Phosphorus in Tropical Soils
}

\author{
L. M. Condron, J. O. Moir, H. Tiessen,* and J. W. B. Stewart
}

\begin{abstract}
The determination of total organic phosphorus (TOP) in soils presents several methodological problems, particularly on strongly weathered and tropical soils. We reviewed the application of several methods for TOP determination to soils from different zones of the globe and evaluated the applicability of one ignition and two extraction methods to tropical soils from Brazil and Ghana. Reproducibility (coefficients of variation) was within $6 \%$ for the ignition method, and $13 \%$ for the extraction methods, due to the simplicity of the former. The two extraction methods produced results similar to each other, while the ignition method generally gave higher TOP contents. Unusually low $C$ to organic $P$ ratios indicate that the ignition method overestimated TOP in several soils. The Bowman extraction method, developed on weakly weathered soils, appeared also suitable for a variety of tropical soils.
\end{abstract}

$\mathrm{N}^{2}$ UMEROUS STUDIES have shown that organic $\mathbf{P}$ plays an important role in $\mathbf{P}$ cycling and plant $P$ nutrition in temperate (Chater and Mattingly, 1980; Harrison, 1982; Sharpley, 1985; Stewart and Tiessen, 1987) and tropical (Acquaye, 1963; Adepetu and Corey, 1976) soils. A more detailed evaluation of the transformations of organic $P$ in strongly weathered soils, which would be required for a prediction of its role in plant nutrition, is hampered by problems associated with the determination of TOP in such soils (Anderson, 1975, 1980; Tiessen, 1989).

The objectives of this study were to (i) present an updated review of methods for determining TOP, particularly for strongly weathered soils, and (ii) evaluate on tropical soils a new rapid extraction-digestion method for determining TOP that has recently been developed by Bowman (1989). The initial evaluations carried out by Bowman (1989) were mainly confined to weakly weathered soils (Mollisols), and indicated that this particular method compared favorably with long-established sequential-extraction techniques and was superior to the ignition method.

\section{LITERATURE REVIEW}

The main purpose of this review is to outline the different techniques that have been developed to determine TOP, and to assess their suitability for use on selected soils from different areas of the world.

Methods developed for the determination of TOP in soil can be divided into two distinct categories, extraction and ignition methods.

\section{Extraction methods}

These methods are based on the extraction of organic $P$ from the soil by sequential treatment with a selection of acid and alkali solvents of varying strengths. The primary function of the acid extraction is to remove binding metal cations

L.M. Condron, Dep. of Soil Science, Lincoln Univ., Canterbury, New Zealand; J.O. Moir, H. Tiessen, and J.W.B. Stewart, Dep. of Soil Science, Univ. of Saskatchewan, Saskatoon, Canada S7N 0W0. Received 10 Oct. 1989. *Corresponding author.

Published in Soil Sci. Soc. Am. J. 54:1261-1266 (1990). such as $\mathrm{Ca}$, while subsequent treatment with alkali is designed to extract the organic components (including $\mathrm{P}$ ) from the soil. Numerous studies have found that several treatments with acid and alkali are required to effect quantitative extraction of organic $\mathbf{P}$ from soil (Anderson, 1975). Sequential-extraction schemes developed over the past $50 \mathrm{yr}$ include combinations of mineral acids (e.g., $\mathrm{HCl}, \mathrm{H}_{2} \mathrm{SO}_{4}$ ), organic acids (e.g., HOAc), strong alkali (e.g., $\mathrm{NaOH}, \mathrm{KOH}$ ), weak alkali (e.g., $\mathrm{NaHCO}_{3}$ ) and chelating agents (e.g., EDTA, oxine, acetylacetone) (Anderson, 1975).

The main shortcomings of the extraction techniques include incomplete extraction and hydrolysis of organic $P$ during extraction, particularly when strong mineral acids such as $12 \mathrm{M} \mathrm{HCl}$ are used (Anderson, 1975; Olsen and Sommers, 1982). The latter has been minimized to a large extent by the adaptation of extraction techniques to include extraction with alkali prior to treatment with strong mineral acid (Anderson, 1960). However, Bowman (1989) showed that treatment with concentrated $(18 \mathrm{M}) \mathrm{H}_{2} \mathrm{SO}_{4}$ caused minimal hydrolysis $(<10 \%)$ of organic $P$ esters (glycerol phosphate, inositol hexaphosphate, nitrophenyl phosphate) added to soil. The technique developed by Mehta et al. (1954) and the adapted version proposed by Anderson (1960) are generally considered the reference or standard extraction methods for TOP.

In view of the time taken in performing the various sequential extractions and in determining organic $P$ in the resulting extracts as total $P$ minus inorganic $P$, the extraction techniques have mainly been used in research studies and have not been widely employed in either soil survey or routine soil testing programs. Attempts have been made to reduce the time involved in extraction techniques by using ultrasonic dispersion in conjunction with strong alkali. While some studies have reported good recoveries of organic P compared with traditional extraction methods (Steward and Oades, 1972; Soltanpour et al., 1987), others have found that, frequently, less than half of the total soil organic $P$ was recovered using rapid ultrasonic extraction techniques (Tate and Newman, 1982; Hawkes et al., 1984).

\section{Ignition Methods}

These methods are based on determining the organic-P content from the difference in acid-extractable inorganic $P$ in unignited and ignited samples of soil. Many different ignition techniques have been developed based on differences in ignition temperature $\left(200-600^{\circ} \mathrm{C}\right)$ and mineral acid type $\left(\mathrm{HCl}\right.$ or $\mathrm{H}_{2} \mathrm{SO}_{4}$ ) and strength $(0.1-12 \mathrm{M}$ ) (Anderson, 1975; Olsen and Sommers, 1982). Nonetheless, the method originally developed by Saunders and Williams (1955) and later adapted by Walker and Adams (1958) is widely regarded as the standard or reference ignition technique for determining TOP.

Compared with the extraction techniques, the ignition method is faster and easier to perform. The ignition method is, consequently, well suited for use with large numbers of soil samples, and it has been widely used in soil surveys and research. While the ignition procedure may be easier to perform, however, several potential sources of error are known to be associated with it, i.e., incomplete oxidation of organic $\mathrm{P}$ during ignition, loss of $\mathrm{P}$ by volatilization during ignition and, most importantly, changes in the acid solubility of soil inorganic $\mathbf{P}$ as a result of ignition (Dormaar and Webster, 1964; Williams et al., 1970; Anderson, 1975). According to the latter, soil minerals containing inorganic $P$ may become soluble in acid following ignition, and irreversible adsorption 
of released inorganic $P$ may occur during extraction of ignited soil. These potential errors are more pronounced in strongly weathered soils than in weakly weathered soils (Williams and Walker, 1967; Williams et al., 1970; Oniani et al., 1973). Furthermore, Williams et al. (1970) found that, in a range of soil and rock materials in New Zealand, the proportion of inorganic $P$ extracted from unignited soil by 0.5 $\mathrm{M} \mathrm{H}_{2} \mathrm{SO}_{4}$ decreased with increasing degree of weathering and concluded that the nonextracted portion of the inorganic $P$ was rendered acid soluble by ignition and thereby resulted in inflated values for TOP in strongly weathered soils.

The remainder of this review deals specifically with selected studies in which the standard ignition (i.e., Saunders and Williams ) and extraction (i.e., Mehta or Anderson) techniques for determining TOP have been compared.

In several studies, close agreement has been found between ignition and extraction values for TOP in soils from Great Britain (Hance and Anderson, 1962), Nigeria (Omotoso and Wild, 1970; Omotoso, 1971; Ipinmindun, 1973) and North America (Dormaar, 1964; Soltanpour et al., 1987; Bowman, 1989). In most of the reported comparative studies, however, ignition values tended to be greater than those obtained by extraction (Anderson, 1960; Enwezor and Moore, 1966; Williams and Walker, 1967; Williams et al., 1970; Oniani et al., 1973). On the other hand, results from humid tropical soils from Costa Rica (Bornemisza and Igue, 1967) and Sri Lanka (Oniani et al., 1973) showed that values obtained for TOP by extraction were markedly greater than those obtained by ignition. Results from tropical soils in Hawaii and Costa Rica showed that the differences between ignition and extraction data for TOP were greater in subsoils than in the corresponding topsoils (Bornemisza and Igue, 1967; Soltanpour et al., 1987).

From the studies cited above, some broad conclusions can be drawn on the relationship between soil characteristics and TOP values obtained with the different methods. In general, the closest agreement between ignition and extraction methods has been found in weakly weathered soils, and in acid soils in which a large proportion of the soil inorganic $P$ is soluble in mineral acid. Ignition values tend to be markedly different from extraction values in more strongly weathered soils (Anderson, 1960; Hance and Anderson, 1962; Williams and Walker, 1967; Williams et al., 1970; Oniani et al., 1973; Bowman, 1989). For example, Williams et al. (1970) found that, in five weakly weathered New Zealand soils, the average TOP determined by ignition $\left(675 \mathrm{mg} \mathrm{kg}^{-1}\right)$ and extraction (636 mg kg-1) were similar, whereas corresponding data from strongly weathered soils showed large differences between TOP determined by ignition ( $284 \mathrm{mg} \mathrm{kg}^{-1}$ ) and extraction (38 $\mathrm{mg} \mathrm{kg}^{-1}$ ).

Oniani et al. (1973) suggested an influence of dithioniteextractable $\mathrm{Fe}\left(\mathrm{Fe}_{\mathrm{d}}\right)$ content on the determination of TOP in soils by ignition and extraction. In selected soils from the USSR and Great Britain containing between 12 and $32 \mathrm{~g}$ $\mathrm{kg}^{-1}$ of $\mathrm{Fe}_{\mathrm{d}}$, values for TOP determined by ignition were consistently greater than those determined by extraction, whereas, in acid tea soils from Sri Lanka that contained greater quantities of $\mathrm{Fe}_{\mathrm{d}}\left(54-58 \mathrm{~g} \mathrm{~kg}^{-1}\right)$, the extraction values were greater than the ignition values.

In this study, we have assessed the performance of one ignition and two extraction methods on several tropical soils.

\section{MATERIALS AND METHODS}

\section{Soils}

The 23 soils selected for this study were taken from northeastern Brazil (20) and Ghana, West Africa (3) and comprised soils from humid and semiarid regions. Samples included examples of the major soil types found in the tropics, i.e., Alfisols, Ultisols, Oxisols, and Vertisols, and covered a wide range of total-P and organic-P contents.

Most of the soil samples were from the A horizon, although one complete profile (Noncalcic Brown A1, A3, B2, and $C$ ) and separated concretionary material from a subsoil horizon were included. The soils and their major chemical characteristics by horizon are shown in Table 1 . All soils were air dried and finely ground $(<150 \mu \mathrm{m})$ prior to analysis.

Table 1. Major chemical characteristics of selected soils from northeastem Brazil (Pernambuco) and Ghana.

\begin{tabular}{|c|c|c|c|c|c|c|c|c|c|c|c|c|c|}
\hline \multirow[b]{2}{*}{$\begin{array}{l}\text { Soil } \\
\text { no. }\end{array}$} & \multirow[b]{2}{*}{ Horizon } & \multirow[b]{2}{*}{ Soil type } & \multirow[b]{2}{*}{$\begin{array}{c}\text { Taxonomic } \\
\text { suborder }\end{array}$} & \multirow[b]{2}{*}{$\begin{array}{c}\mathbf{p H} \\
\left(\mathbf{H}_{2} \mathbf{O}\right)\end{array}$} & \multirow[b]{2}{*}{$\underset{\mathrm{C}}{\text { Organic }}$} & \multirow[b]{2}{*}{$\begin{array}{c}\text { Total } \\
\mathbf{N}\end{array}$} & \multirow[b]{2}{*}{$\underset{\mathbf{P}}{\text { Total }}$} & \multicolumn{2}{|c|}{$\begin{array}{c}\text { Exchangeable } \\
\text { cations }\end{array}$} & \multicolumn{2}{|c|}{ Oxalate } & \multicolumn{2}{|c|}{ Citrate-dithionite } \\
\hline & & & & & & & & A] & $\begin{array}{c}\mathbf{C a}+ \\
\mathbf{M g}+\mathbf{K}\end{array}$ & Al & $\mathbf{F e}$ & Al & $\mathbf{F e}$ \\
\hline & & & & & $\mathrm{g} \mathrm{kg}^{-1}$ & \multicolumn{2}{|c|}{$\mathrm{mg} \mathrm{kg}^{-1} \longrightarrow$} & \multicolumn{2}{|c|}{$-\mathrm{cmol}_{\mathrm{c}} \mathrm{kg}^{-1}$} & \multicolumn{4}{|c|}{$-\mathbf{g ~ k g}^{-1}$} \\
\hline 1 & $\mathbf{A}$ & RY† Podzolic & Udult & 5.7 & 8.2 & 496 & 40 & 0.9 & 13 & 0.42 & 0.32 & 0.28 & 0.3 \\
\hline 2 & Bc $\ddagger$ & RY Podzolic & Udult & 4.9 & 9.7 & 206 & 88 & 10.8 & 1 & 7.09 & 0.31 & 4.12 & 0.8 \\
\hline 3 & $\mathbf{A}$ & RY Podzolic (eutrophic) & Udult & 6.6 & 17.1 & 1184 & 638 & 0.1 & 89 & 0.98 & 1.74 & 2.02 & 25.0 \\
\hline 4 & $\mathbf{A}$ & RY Latosol (humic) & Humox & 5.2 & 16.3 & 756 & 131 & 9.5 & 26 & 1.44 & 0.91 & 1.76 & 8.1 \\
\hline 5 & $\mathbf{A}$ & Terra Roxa (eutrophic) & Udult & 5.3 & 22.9 & 1169 & 1588 & 3.2 & 50 & 1.78 & 5.11 & 6.40 & 77.5 \\
\hline 6 & $\mathbf{A}$ & Vertisol & Torrert & 7.6 & 17.8 & 1690 & 420 & 0.3 & 447 & 1.94 & 4.09 & 1.24 & 13.6 \\
\hline 7 & A1 & Noncalcic brown & Xeralf & 7.2 & 5.8 & 570 & 632 & 0.1 & 80 & 0.69 & 1.68 & 1.01 & 16.3 \\
\hline 8 & A3 & Noncalcic brown & Xeralf & 6.7 & 4.2 & 573 & 464 & 0.2 & 96 & 0.18 & 1.85 & 1.18 & 19.9 \\
\hline 9 & B2 & Noncalcic brown & Xeralf & 7.2 & 3.7 & 466 & 296 & 0.0 & 185 & 1.05 & 1.81 & 1.99 & 29.8 \\
\hline 10 & C & Noncalcic brown & Xeralf & 7.9 & 1.2 & 164 & 1374 & 0.0 & 246 & 0.78 & 1.12 & 1.07 & 13.3 \\
\hline 11 & $\mathbf{A}$ & Vertisol & Xerert & 7.5 & 10.0 & 923 & 789 & 0.1 & 497 & 1.87 & 1.78 & 0.94 & 5.1 \\
\hline 12 & $\mathbf{A}$ & RY Latosol & Ustox & 5.1 & 15.3 & 1017 & 139 & 5.5 & 14 & 1.02 & 2.39 & 1.55 & 10.6 \\
\hline 13 & $\mathbf{A}$ & RY Latosol & Ustox & 5.3 & 8.7 & 493 & 84 & 2.9 & 10 & 1.07 & 2.37 & 1.44 & 10.7 \\
\hline 14 & A & Savannah Ochrosol \& & Ustalf & 6.6 & 7.0 & 896 & 166 & 0.1 & 57 & 0.32 & 0.59 & 0.85 & 1.1 \\
\hline 15 & Ac $¥$ & Savannah Ochrosol $\S$ & Ustalf & 6.7 & 4.0 & 408 & 843 & 0.1 & 40 & 0.64 & 1.58 & 10.2 & 199 \\
\hline 16 & $A$ & Savannah Gleisol $\S$ & Aquept & 5.5 & 3.8 & 306 & 68 & 4.0 & 12 & 0.28 & 0.70 & 0.18 & 0.9 \\
\hline 17 & $\mathbf{A}$ & RY Latosol (distrophic) & Orthox & 5.5 & 21.1 & 1800 & 211 & 1.0 & 64 & - & - & - & - \\
\hline 18 & $\mathbf{A}$ & RY Podzolic & Udult & 4.1 & 15.6 & 1300 & 154 & 7.0 & 15 & - & - & - & - \\
\hline 19 & $\mathbf{A}$ & Terra Roxa (distrophic) & Udult & 4.9 & 21.6 & 1000 & 1466 & 3.0 & 5 & - & - & - & - \\
\hline 20 & $\mathbf{A}$ & Noncalcic brown & Xeralf & 4.8 & 11.5 & 1044 & 509 & 2.7 & 78 & 1.01 & 4.96 & 1.43 & 14.0 \\
\hline 21 & $\mathbf{A}$ & Brunizem & Ustalf & 5.7 & 17.7 & 2316 & 190 & 0.2 & 128 & 1.42 & 1.97 & 1.46 & 11.2 \\
\hline 22 & $\mathbf{A}$ & Terra Roxa (distrophic) & Udalf & 5.9 & 18.8 & 1590 & 456 & 0.1 & 71 & 1.34 & 2.29 & 2.96 & 36.3 \\
\hline 23 & $\mathbf{A}$ & RY Podzolic & Udult & 6.1 & 8.7 & 1120 & 337 & 0.5 & 63 & 1.10 & 2.85 & 1.24 & 11.3 \\
\hline
\end{tabular}

t RY $=$ Red-yellow.

$\mp$ Concretionary material.

$\$$ Soils from the Savannah zone of Ghana, all others from Brazil. 
Total soil $\mathrm{P}$ was determined by carbonate fusion ( $\mathrm{Lim}$ and Jackson, 1982).

\section{Methods for Determining Total Soil Organic Phosphorus}

Amounts of TOP in the selected soils were determined using three different methods:

1. Saunders-Williams ignition method (Saunders and Williams, 1955; Walker and Adams, 1958$)\left(550^{\circ} \mathrm{C}, 1\right.$ $M \mathrm{H}_{2} \mathrm{SO}_{4}$ ).

2. Anderson-Mehta extraction method, slightly modified from that described by Anderson (1960). A sample of $0.5 \mathrm{~g}$ of soil was shaken with $30 \mathrm{~mL}$ of $0.3 \mathrm{M} \mathrm{NaOH}$ for $16 \mathrm{~h}$. The soil suspension was centrifuged (relative centrifugal force $12500 \mathrm{~g}, 10 \mathrm{~min}$ ) and the supernatant decanted into a $100-\mathrm{mL}$ volumetric flask. The soil residue was then heated with $10 \mathrm{~mL}$ of concentrated (11.3 $M) \mathrm{HCl}$ in a water bath at $82^{\circ} \mathrm{C}$ for $10 \mathrm{~min}$. A further $5 \mathrm{~mL}$ of concentrated $\mathrm{HCl}$ was added and allowed to stand for $1 \mathrm{~h}$ at room temperature with regular vortex shaking. The soil suspension was centrifuged and the supernatant decanted and made to volume $(50 \mathrm{~mL})$ with deionized water. The soil residue was next shaken with $20 \mathrm{~mL}$ of $0.5 \mathrm{M} \mathrm{NaOH}$ and allowed to stand for $1 \mathrm{~h}$ at room temperature with regular vortex shaking. The soil suspension was centrifuged and the supernatant added to previous alkali extract. The soil residue was again shaken with $30 \mathrm{~mL}$ of $0.5 \mathrm{M} \mathrm{NaOH}$, covered and heated at $82{ }^{\circ} \mathrm{C}$ in an oven for $8 \mathrm{~h}$ and allowed to cool. The soil suspension was centrifuged and the supernatant added to the two previous alkali extracts and made to volume $(100 \mathrm{~mL})$ with deionized water. Inorganic, total, and organic $P$ in the acid and alkali extracts were determined according to the methods outlined by Tiessen et al. (1983). Total soil organic P was determined as the sum of the organic $P$ in the acid and alkali extracts.

3. Bowman extraction method, slightly modified from that described by Bowman (1989). A 2-g soil sample was placed into a $250-\mathrm{mL}$ plastic centrifuge tube and $3 \mathrm{~mL}$ of concentrated $(18 \mathrm{M}) \mathrm{H}_{2} \mathrm{SO}_{4}$ was added via a long-stemmed funnel while mixing gently. Four separate $1-\mathrm{mL}$ aliquots of deionized water were added with shaking between each addition, followed by a further $41 \mathrm{~mL}$ of deionized water (total volume $48 \mathrm{~mL}$ ). The soil suspension was cooled and centrifuged, and the supernatant Millipore filtered (Millipore Corp., Bedford, MA) at $45 \mu \mathrm{m}$. The soil was washed with deionized water and centrifuged, and the supernatant discarded. The soil residue (including the millipore filter from the acid extract) was then shaken with $98 \mathrm{~mL}$ of $0.5 \mathrm{M} \mathrm{NaOH}$ for $2 \mathrm{~h}$ at room temperature. The soil suspension was centrifuged and the supernatant millipore filtered. Inorganic, total, and organic $\mathbf{P}$ in the acid and alkali extracts were determined and total soil organic $P$ was calculated as the sum of organic $P$ in the acid and alkali extracts.

To enable statistical analysis of the reproducibility of values obtained for TOP by the different methods, four replicate samples of each soil were used for each method under investigation.

\section{RESULTS AND DISCUSSION}

The soils selected for this study were predominantly acidic $(\mathrm{pH}<6)$ and contained small amounts of organic $\mathrm{C}\left(1-23 \mathrm{~g} \mathrm{~kg}^{-1}\right)$ and total $\mathrm{N}\left(0.2-2.3 \mathrm{~g} \mathrm{~kg}^{-1}\right.$ ) (Table 1). Total $P$ ranged from 40 to $1588 \mathrm{mg} \mathrm{kg}^{-1}$, with an overall average of $482 \mathrm{mg} \mathrm{kg}^{-1}$ (Table 1). The greatest amounts of total $\mathrm{P}$ were found in the eutrophic Terra
Table 2. Amounts of total P extracted from soils by the SaundersWilliams (SW), Anderson-Mehta (AM), and Bowman (BOW) methods.

\begin{tabular}{|c|c|c|c|c|c|c|}
\hline \multirow[t]{2}{*}{$\begin{array}{l}\text { Soil } \\
\text { no. }\end{array}$} & \multicolumn{2}{|c|}{ SW } & \multicolumn{2}{|c|}{$\mathbf{A M}$} & \multicolumn{2}{|c|}{ BOW } \\
\hline & $\mathrm{mg} \mathrm{kg}^{-1}$ & $\begin{array}{c}\% \text { of } \\
\text { total }\end{array}$ & $\mathrm{mg} \mathrm{kg}^{-1}$ & $\begin{array}{c}\% \text { of } \\
\text { totalt }\end{array}$ & $\mathrm{mg} \mathrm{kg} \mathrm{kg}^{-1}$ & $\begin{array}{l}\% \text { of } \\
\text { totalł }\end{array}$ \\
\hline 1 & 34 & 85 & 35 & 87 & 28 & 71 \\
\hline 2 & 58 & 66 & 43 & 49 & 26 & 30 \\
\hline 3 & 375 & 59 & 607 & 95 & 616 & 97 \\
\hline 4 & 102 & 78 & 126 & 96 & 102 & 78 \\
\hline 5 & 1492 & 94 & 1202 & 76 & 843 & 53 \\
\hline 6 & 404 & 96 & 387 & 92 & 412 & 98 \\
\hline 7 & 522 & 83 & 622 & 98 & 587 & 93 \\
\hline 8 & 356 & 77 & 445 & 96 & 390 & 84 \\
\hline 9 & 197 & 67 & 285 & 96 & 162 & 55 \\
\hline 10 & 1395 & 102 & 1497 & 109 & 1476 & 107 \\
\hline 11 & 766 & 97 & 849 & 108 & 829 & 105 \\
\hline 12 & 90 & 68 & 140 & 101 & 97 & 70 \\
\hline 13 & 70 & 84 & 85 & 101 & 63 & 75 \\
\hline 14 & 151 & 91 & 167 & 101 & 170 & 102 \\
\hline 15 & 461 & 55 & 847 & 100 & 266 & 32 \\
\hline 16 & 44 & 65 & 58 & 85 & 39 & 57 \\
\hline 17 & 169 & 80 & 179 & 85 & 159 & 76 \\
\hline 18 & 134 & 87 & 154 & 100 & 114 & 74 \\
\hline 19 & 1180 & 81 & 1021 & 70 & 784 & 54 \\
\hline 20 & 446 & 88 & 495 & 97 & 507 & 100 \\
\hline 21 & 171 & 90 & 191 & 101 & 183 & 97 \\
\hline 22 & 356 & 78 & 440 & 97 & 391 & 86 \\
\hline 23 & 267 & 79 & 299 & 89 & 283 & 84 \\
\hline Arithmetic & 402 & 83 & 442 & 92 & 371 & 77 \\
\hline means & & & & & & \\
\hline
\end{tabular}

† See Table 1 for descriptions.

$\ddagger$ Percentage of total soil $P$, as determined by fusion.

Roxa (no. 5, $1588 \mathrm{mg} \mathrm{kg}^{-1}$ ), Noncalcic Brown C (no. $10,1374 \mathrm{mg} \mathrm{kg}^{-1}$ ) and the distrophic Terra Roxa (no. $19,1466 \mathrm{mg} \mathrm{kg}^{-1}$ ) soils. The concretionary material in the Savannah Ochrosol (no. 15) contained markedly more total $P\left(843 \mathrm{mg} \mathrm{kg}^{-1}\right)$ than the corresponding nonconcretionary material (no. $\left.14,166 \mathrm{mg} \mathrm{kg}^{-1}\right)$ (Table 1).

Amounts of total $\mathbf{P}$ extracted by the methods under investigation are shown in Table 2 . In general, these results show that a greater proportion of the total soil $P$ was extracted using the Anderson-Mehta method (mean 91.7\%) than by either the Saunders-Williams (mean $83.4 \%$ ) or Bowman (mean $76.9 \%$ ) methods. These data cannot be directly compared with the data of Bowman (1989), since no total soil P or extracted total $P$ data was included, although they are consistent with the findings of Bornemisza and Igue (1967) for the Mehta and Saunders-Williams methods in soils from Costa Rica. The lowest overall recovery of total $P$ by the three methods occurred in the concretionary material (no. 2, 29.9-66.4\%).

Amounts of TOP determined by the Saunders-Williams ignition method (range $23-1253 \mathrm{mg} \mathrm{kg}^{-1}$, mean $209 \mathrm{mg} \mathrm{kg}^{-1}$ ) were substantially greater than the corresponding amounts determined by the AndersonMehta (range 13-206 mg kg-1, mean $78 \mathrm{mg} \mathrm{kg}^{-1}$ ) and the Bowman (range 9-248 mg kg-1, mean $88 \mathrm{mg} \mathrm{kg}^{-1}$ ) extraction methods (Table 3 ). Total organic $\mathbf{P}$ determined by the Saunders-Williams, Anderson-Mehta, and Bowman methods, therefore, represented an average of 43,16 , and $18 \%$ of the total soil $P$, respectively (Tables 1 and 3 ).

Differences between the Saunders-Williams and An- 
Table 3. Amounts of organic P extracted from soils by the SaundersWilliams (SW), Anderson-Mehta (AM) and Bowman (BOW) methods.

\begin{tabular}{|c|c|c|c|c|c|c|c|}
\hline \multirow{3}{*}{$\begin{array}{l}\text { Soil } \\
\text { no. } t\end{array}$} & \multicolumn{7}{|c|}{ Organic $P$ extracted } \\
\hline & \multicolumn{2}{|c|}{ sw } & \multicolumn{2}{|c|}{$\mathbf{A M}$} & \multicolumn{2}{|c|}{ BOW } & \multirow[t]{2}{*}{ LSD } \\
\hline & $\mathbf{m g ~ \mathbf { ~ k g } ^ { - 1 }}$ & CV\% & $\mathbf{m g ~ k g} \mathbf{~}^{-1}$ & CV\% & $\mathbf{m g} \mathbf{k g}^{-1}$ & CV\%‡ & \\
\hline 1 & 23.6 & 5.5 & 13.0 & 40 & 9.2 & 17 & 5.2 \\
\hline 2 & 50.6 & 9.5 & 13.2 & 24 & 12.0 & 13 & 5.5 \\
\hline 3 & 180 & 2.9 & 101 & 13 & 125 & 10 & 17.2 \\
\hline 4 & 75.1 & 1.3 & 49.1 & 20 & 43.8 & 7.8 & 9.6 \\
\hline 5 & 1253 & 2.2 & 188 & 1.3 & 193 & 3.7 & 42.2 \\
\hline 6 & 221 & 2.1 & 110 & 3.6 & 178 & 4.1 & 8.8 \\
\hline 7 & 161 & 14 & 78.2 & 6.6 & 109 & 14 & 25.2 \\
\hline 8 & 156 & 5.3 & 67.4 & 7.0 & 90.4 & 14 & 12.4 \\
\hline 9 & 117 & 3.1 & 40.2 & 20 & 43.4 & 10 & 9.0 \\
\hline 10 & 58.3 & 20 & 16.3 & 29 & 63.8 & 21 & 17.0 \\
\hline 11 & 72.6 & 22 & 91.8 & 4.1 & 81.6 & 14 & NS \\
\hline 12 & 57.4 & 12 & 44.3 & 21 & 34.0 & 22 & 12.9 \\
\hline 13 & 47.0 & 5.3 & 25.8 & 20 & 22.7 & 12 & 5.8 \\
\hline 14 & 111 & 1.2 & 71.6 & 3.6 & 79.8 & 3.9 & 3.9 \\
\hline 15 & 341 & 3.5 & 26.2 & 34 & 24.8 & 21 & 14.5 \\
\hline 16 & 34.6 & 11 & 32.8 & 30 & 22.0 & 11 & NS \\
\hline 17 & 117 & 3.8 & 81.8 & 10 & 68.2 & 6.7 & 9.8 \\
\hline 18 & 99.8 & 2.0 & 54.1 & 15 & 38.1 & 9.2 & 8.3 \\
\hline 19 & 952 & 2.0 & 206 & 3.3 & 248 & 16 & 40.5 \\
\hline 20 & 172 & 4.8 & 134 & 11 & 166 & 9.8 & 21.1 \\
\hline 21 & 131 & 4.4 & 102 & 5.8 & 104 & 4.6 & 8.8 \\
\hline 22 & 223 & 2.3 & 145 & 4.8 & 159 & 6.5 & 12.5 \\
\hline 23 & 149 & 5.5 & 106 & 12 & 108 & 8.1 & 15.8 \\
\hline $\begin{array}{l}\text { Arithmetic } \\
\text { means }\end{array}$ & 208 & 6.4 & 78 & 15 & 88 & 11 & - \\
\hline
\end{tabular}

† See Table 1 for descriptions.

₹ Coefficient of variation on mean of four extractions.

$\S$ Fisher's protected least significant difference at $\boldsymbol{P} \leq 0.05$ (horizontal comparison only).

derson-Mehta/Bowman methods were statistically significant $(P<0.05)$ in 21 of the 23 soils examined (except in the Vertisol [no. 11] and Savannah Gleisol [no. 16] soils) (Table 3). The differences observed between the three methods in the Noncalcic Brown C horizon (no. 10) (Table 3) were probably erroneous due to the small amount of TOP relative to acid-extractable inorganic P (Ca-bound P) (>1300 mg kg-1) in this subsoil (Table 4). Similar quantities of TOP were determined by the Anderson-Mehta and Bowman methods in 10 soils. In seven other soils, significant differences were found between the Anderson-Mehta and Bowman methods, although corresponding differences from TOP determined by the Saunders-Williams method (Table 3) were much greater. Nonetheless, large differences in TOP were observed between the Anderson-Mehta and Bowman methods in the Vertisol (no. 6) and Noncalcic Brown (no. 20) soils (Table 3).

The greater values for TOP determined by ignition than by extraction in these strongly weathered soils are consistent with several other studies on similar soil types (Enwezor and Moore, 1966; Williams et al., 1970). To test the role of dithionite-extractable Fe suggested by Oniani et al. (1973), we correlated Al and Fe contents (Table 1) with the ratio of ignition to extractable (Bowman) TOP, and obtained correlation coefficients $\left(r^{2}\right)$ of 0.89 and 0.82 with dithionite-extractable $\mathrm{Al}$ and $\mathrm{Fe}$, respectively. This indicates that the ignition method measures higher apparent TOP values in soils with high dithionite-extractable $A 1$ and Fe contents, a result opposite to the one obtained by Oniani et al. (1973) in their comparison between temperate and tropical soils. The high correlation, though,
Table 4. Relative proportions of total organic $P$ extracted by component acid and alkali reagents in Anderson-Mehta (AM) and Bowman (BOW) methods.

\begin{tabular}{|c|c|c|c|c|c|}
\hline \multirow[b]{2}{*}{ Soil no.† } & \multicolumn{3}{|c|}{ AM } & \multicolumn{2}{|c|}{ Bows } \\
\hline & $\mathrm{NaOH} I$ & $\mathrm{HCl}$ & $\mathrm{NaOH}$ II & $\mathrm{H}_{2} \mathrm{SO}_{4}$ & $\mathrm{NaOH}$ \\
\hline & & & $-\%$ & 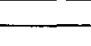 & 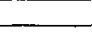 \\
\hline 1 & 75 & 10 & 15 & 70 & 30 \\
\hline 2 & 75 & 2 & 23 & 88 & 12 \\
\hline 3 & 55 & 30 & 15 & 88 & 12 \\
\hline 4 & 71 & 6 & 23 & 84 & 16 \\
\hline 5 & 59 & 12 & 39 & 86 & 14 \\
\hline 6 & 19 & 47 & 34 & 80 & 20 \\
\hline 7 & 39 & 19 & 42 & 91 & 9 \\
\hline 8 & 45 & 17 & 38 & 90 & 10 \\
\hline 9 & 27 & 17 & 56 & 79 & 21 \\
\hline 10 & 72 & 0 & 28 & 86 & 14 \\
\hline 11 & 17 & 38 & 45 & 62 & 38 \\
\hline 12 & 62 & 9 & 29 & 80 & 20 \\
\hline 13 & 64 & 14 & 22 & 89 & 11 \\
\hline 14 & 53 & 23 & 24 & 86 & 14 \\
\hline 15 & 96 & 0 & 4 & 91 & 9 \\
\hline 16 & 60 & 5 & 35 & 85 & 15 \\
\hline 17 & 74 & 7 & 19 & 83 & 17 \\
\hline 18 & 57 & 8 & 35 & 85 & 15 \\
\hline 19 & 83 & 6 & 11 & 86 & 14 \\
\hline 20 & $\begin{array}{l}53 \\
58\end{array}$ & 17 & 25 & 87 & 13 \\
\hline 21 & 71 & 14 & 15 & 72 & 28 \\
\hline 22 & 63 & 19 & 18 & 86 & 14 \\
\hline 23 & 68 & 14 & 18 & 83 & 17 \\
\hline $\begin{array}{c}\text { Arithmetic } \\
\text { means }\end{array}$ & 59 & 14 & 27 & 83 & 17 \\
\hline
\end{tabular}

† See Table 1 for descriptions.

$\neq \mathrm{NaOH}$ I $(0.3 \mathrm{M} \mathrm{NaOH}) ; \mathrm{HCl}(12 \mathrm{M} \mathrm{HCl}) ; \mathrm{NaOH}$ II $\left(0.5 \mathrm{M} \mathrm{NaOH}, 90^{\circ} \mathrm{C}\right)$. $\S \mathrm{H}_{2} \mathrm{SO}_{4}\left(18 \mathrm{M} \mathrm{H}_{2} \mathrm{SO}_{4}\right) ; \mathrm{NaOH}(0.5 \mathrm{M} \mathrm{NaOH})$.

is almost entirely dependent on Samples 2, 5, and 15, greatly reducing the significance of this result.

The reproducibility of the different methods can be assessed from the respective coefficients of variation (CV\%) associated with the determination of TOP in four replicate samples of each soil. These data (Table 3) demonstrate that greater variability occurred with the multiple-extraction Anderson-Mehta (mean CV $15 \%$ ) and Bowman (mean CV 11\%) methods than with the Saunders-Williams ignition method (mean CV $6.4 \%$ ). This may be at least partly attributed to the relative simplicity of the Saunders-Williams technique, which involved only one extraction of unignited and ignited soil with $1 \mathrm{M} \mathrm{H}_{2} \mathrm{SO}_{4}$, while the Bowman and Anderson-Mehta methods involved two and four separate sequential extraction steps, respectively. Increased analytical error may, therefore, be associated with the dispensing and separation of different soil extractants and the determination of inorganic and total $\mathrm{P}$ in the component acid and alkali extracts of the Anderson-Mehta and Bowman methods. Bowman (1989) also found that the variability associated with both extraction methods was slightly greater than with the Saunders-Williams method.

The respective proportions of total soil organic $P$ extracted by the component acid and alkali extractants in the Anderson-Mehta and Bowman methods are shown in Table 4. In the Bowman method, most (62$91 \%$, mean $83 \%$ ) of the TOP was extracted by the initial treatment with concentrated $\mathrm{H}_{2} \mathrm{SO}_{4}$. A similar finding was reported by Bowman (1989) for a range of North American soils. In the Anderson-Mehta method, 17 to $96 \%$ (mean $59 \%$ ) of the TOP was ex- 
Table 5. Ratios of organic $C$ to total $N(C / N)$ and organic $C$ to organic $P\left(C / P_{0}\right)$ as determined by the Saunders-Williams ( $\left.S W\right)$, Anderson-Mehta (AM), and Bowman (BOW) methods.

\begin{tabular}{crrrr}
\hline & & \multicolumn{3}{c}{ C/P } \\
\cline { 3 - 5 } Soil no. & C/N & SW & AM & BOW \\
\hline 1 & 16.5 & 347 & 631 & 891 \\
2 & 47.1 & 192 & 735 & 808 \\
3 & 14.4 & 95 & 170 & 137 \\
4 & 21.6 & 217 & 332 & 372 \\
5 & 19.6 & 18 & 122 & 118 \\
6 & 10.5 & 81 & 161 & 100 \\
7 & 10.2 & 36 & 74 & 53 \\
8 & 7.3 & 27 & 62 & 47 \\
9 & 7.9 & 32 & 92 & 85 \\
10 & 7.3 & 21 & 74 & 19 \\
11 & 10.8 & 138 & 109 & 123 \\
12 & 15.0 & 267 & 345 & 450 \\
13 & 17.6 & 185 & 337 & 383 \\
14 & 7.8 & 63 & 98 & 88 \\
15 & 9.8 & 12 & 153 & 161 \\
16 & 12.4 & 103 & 116 & 173 \\
17 & 11.7 & 181 & 258 & 309 \\
18 & 12.0 & 156 & 288 & 409 \\
19 & 21.6 & 23 & 105 & 87 \\
20 & 11.0 & 67 & 86 & 69 \\
21 & 7.6 & 135 & 173 & 170 \\
22 & 11.8 & 84 & 130 & 118 \\
23 & 7.8 & 59 & 82 & 81 \\
Means; & 12.9 & 115 & 196 & 219 \\
\hline
\end{tabular}

+ See Table 1 for descriptions.

¥ A horizon soils only (i.e., excluding soils no. 2,9 , and 10 ).

tracted by the first alkali extract $(0.3 \mathrm{M} \mathrm{NaOH})$. It is noteworthy that the smallest proportions of TOP extracted by $0.3 M \mathrm{NaOH}$ in the Anderson-Mehta method occurred in the two Vertisols (no. 6 and 11; $19 \%$ and $17 \%$ ). This was compensated by greater proportions of TOP extracted by the subsequent concentrated-HCl step (38-47\%).

The ratios of organic $C$ to total $N(C / N)$ and organic $\mathrm{C}$ to organic $\mathrm{P}\left(\mathrm{C} / \mathrm{P}_{\mathrm{o}}\right)$ as determined by the three methods under investigation are shown in Table 5 . The $\mathrm{C} /$ $\mathrm{N}$ ratio varied from 7.3 to 47.1 with a mean of 12.9 , which is consistent with values reported for most soils of 10 to 12 (Stevenson, 1982). As expected, the $C / P_{o}$ ratios were markedly greater when the organic $\mathbf{P}$ was determined by the Anderson-Mehta (62-631, mean 196) and Bowman (19-891, mean 219) methods, compared with the Saunders-Williams method (12-347, mean 115). Ratios of $C / P_{0}$ reported for microbes range from 15 to 45, while those of temperate soils are usually above 50 (Stewart and Tiessen, 1987). Simple correlation coefficients between $C / N$ and $C / P_{0}$ ratios were $0.37,0.75$, and 0.66 when $P_{o}$ was determined by the Saunders-Williams, Anderson-Mehta, and Bowman methods, respectively. The rather low $C / P_{o}$ values and low correlation with $\mathrm{C} / \mathrm{N}$ ratios obtained by the Saunders-Williams method would suggest that this method overestimates $\mathrm{P}_{\mathrm{o}}$. The Bowman method gives a low $\mathrm{C} / \mathrm{P}_{\mathrm{o}}$ in only one soil, the Anderson-Mehta method in none.

These results clearly show that the apparent $C / P_{0}$ ratio in strongly weathered soils will be determined, to a large extent, by the method used to determine organic P. It is, therefore, very difficult to compare data from different studies. For example, Neptune et al. (1975) reported that, in four subtropical agricultural soils from São Paulo state in Brazil, the $C / P_{o}$ ratio ranged from 45 to 247 , using an ignition method to determine total soil organic $\mathbf{P}$.

\section{CONCLUSIONS}

Results of this study demonstrate that the high-temperature ignition (Saunders-Williams) method for determining total organic $P$ in strongly weathered tropical soils substantially overestimates soil organic$P$ content, compared with values obtained by combined acid-alkali extraction techniques (AndersonMehta and Bowman methods).

In general, there was little difference between the amounts of organic $\mathrm{P}$ determined by the AndersonMehta and Bowman methods. Since the Bowman method is faster and involves fewer technical manipulations than the Anderson-Mehta method, it may be the preferred method for use in soil nutrient surveys and where available technical and manpower resources are limited. However, the proportion of total soil $\mathrm{P}$ recovered by extraction was greater with the Anderson-Mehta method than with the Bowman method. This may account for the slightly greater amounts of organic P determined by Anderson-Mehta, compared with Bowman, in many of the soils studied. This, in turn, implies that a fraction of the organic $P$ in these strongly weathered soils may only be extracted from the soil with hot alkali $(0.5 M \mathrm{NaOH})$. Accordingly, in strongly weathered tropical soils, the alkali extraction step of the Bowman method could be carried out at 80 to $90^{\circ} \mathrm{C}$. A similar adaptation was suggested by Bowman (1989) for strongly acid soils.

A very high proportion of the total soil organic $P$ determined by the Bowman method was extracted during the initial treatment with concentrated $\mathrm{H}_{2} \mathrm{SO}_{4}$ (62-91\% overall, $79-91 \%$ for 20 of the 23 soils) (Table 4). It may, therefore, be possible to use this acid-extractable organic-P fraction as a rapid single-step method of determining organic $P$ in short-term studies of soil $\mathrm{P}$ transformations under different management systems in the tropics.

\section{ACKNOWLEDGMENTS}

This study was facilitated by the Canadian International Development Agency and supported by Canadian NSERC grant no. OGP 2274. Thanks are due to Ms. B. Chow for technical assistance. This is Saskatchewan Institute of Pedology Publication no. R621.

\section{REFERENCES}

Acquaye, D.K. 1963. Some significance of soil organic phosphorus mineralization in the phosphorus nutrition of cocoa in Ghana. Plant Soil 19:65-80.

Adepetu, J.A., and R.B. Corey. 1976. Organic phosphorus as a predictor of plant available phosphorus in soils of southern Nigeria. Soil Sci. 122:159-164.

Anderson, G. 1960. Factors affecting the estimation of phosphate esters in soil. J. Sci. Food Agric. 9:497-503.

Anderson, G. 1975. Other organic phosphorus compounds. p. 305331. In J.E. Geiseking (ed.) Soil components. Vol. 1. SpringerVerlag, New York.

Anderson, G. 1980. Assessing organic phosphorus in soils. p. $411-$ 432. In F.E. Khasawneh et al. (ed.) The role of phosphorus in agriculture. ASA, Madison, WI.

Bornemisza, E., and K. Igue. 1967. Comparison of three methods for determining organic phosphorus in Costa Rican soils. Soil Sci. 103:347-353.

Bowman, R.A. 1989. A sequential extraction procedure with concentrated sulphuric acid and dilute base for soil organic phos- 
phorus. Soil Sci. Soc. Am. J. 53:362-366.

Chater, M., and G.E.G. Mattingly. 1980. Changes in organic phosphorus contents of soils from long-continued experiments at Rothamsted and Saxmundham. p. 41-46. In Rothamsted Rep. for 1979. Part 2. Rothamsted Exp. Stn., Harpenden, Herts, UK

Dormaar, J.R. 1964. Evaluation of methods for determination of total organic phosphorus in chernozemic soils of southern Alberta. Can. J. Soil Sci. 44:265-271.

Dormaar, J.F., and G.R. Webster. 1964. Losses inherent in ignition procedures for determining total organic phosphorus. Can. J. Soil Sci. 44:1-6.

Enwezor, W.O., and A.W. Moore. 1966. Comparison of two methods for determining organic phosphorus in some Nigerian soils. Soil Sci. 102:284-285.

Hance, R.J., and G. Anderson. 1962. A comparative study of methods for estimating soil organic phosphate. J. Soil Sci. 13:225-230.

Harrison, A.F. 1982. Labile organic phosphorus mineralization in relation to soil properties. Soil Biol. Biochem. 14:343-351.

Hawkes, G.E., D.S. Powlson, E.W. Randall, and K.R. Tate. 1984. A ${ }^{31} \mathrm{P}$ nuclear magnetic resonance study of the phosphorus species in alkali extracts of soils from long-term field experiments. J. Soil Sci. 35:35-45.

Ipinmidun, W.B. 1973. Comparison of some methods for determining organic phosphorus in some Nigerian soils. Soil Sci. 115:324-325.

Lim, C.H., and M.L. Jackson. 1982. Dissolution for total elemental analysis. p. 1-12. In A.L. Page et al. (ed.) Methods of soil analysis. Part 2. 2nd ed. Agron. Monogr. 9. ASA and SSSA, Madison, WI.

Mehta, N.C., J.O. Legg, C.A.I. Goring, and C.A. Black. 1954. Determination of organic phosphorus in soils. I. Extraction method. Soil Sci. Soc. Am. Proc. 18:443-449.

Neptune, A.M.L., M.A. Tabatabai, and J.J. Hanway. 1975. Sulfur fractions and carbon-nitrogen-phosphorus-sulfur relationships in some Brazilian and Iowa soils. Soil Sci. Soc. Am. Proc. 39:51-55.

Olsen, S.R., and L.E. Sommers. 1982. Phosphorus. p. 403-430. In A.L. Page et al. (ed.) Methods of soil analysis. Part. 2. 2nd ed. Agron. Monogr. 9. ASA and SSSA, Madison, WI.

Omotoso, T.I. 1971. Organic phosphorus contents of some cocoa growing soils of southern Nigeria. Soil Sc. 112:195-199.
Omotoso, T.I., and A. Wild. 1970. Content of inositol phosphates in some English and Nigerian soils. J. Soil Sci. 21:216-223.

Oniani, O.G., M. Chater, and G.E.G. Mattingly. 1973. Some effects of fertilizers and farmyard manure on the organic phosphorus in soils. J. Soil Sci. 24:1-9.

Saunders, W.M.H., and E.G. Williams. 1955. Observations on the determination of total organic phosphorus in soils. J. Soil Sci. 6:247-267.

Sharpley, A.N. 1985. Phosphorus cycling in unfertilized agricultural soils. Soil Sci. Soc. Am. J. 49:905-911.

Soltanpour, P.H., R.L. Fox and R.C. Jones. 1987. A quick method to extract organic phosphorus from soils. Soil Sci. Soc. Am. J. $51: 255-256$.

Stevenson, F.J. 1982. Humus chemistry-Genesis, composition, reactions. Wiley Interscience, New York.

Steward, J.H., and J.M. Oades. 1972. The determination of organic phosphorus in soils. J. Soil Sci. 23:38-49.

Stewart, J.W.B., and H. Tiessen. 1987. Dynamics of soil organic phosphorus. Biogeochemistry 4:41-60.

Tate, K.R., and R.H. Newman. 1982. Phosphorus fractions of a climosequence of soils in New Zealand tussock grassland. Soil Biol. Biochem. 14:191-196.

Tiessen, H. 1989. Soil phosphorus. p. 113-126. In J.M. Anderson and J.S.I. Ingram (ed.) Tropical soil biology and fertility: A handbook of methods. C.A.B. International, Oxford.

Tiessen, H., J.W.B. Stewart, and J.O. Moir. 1983. Changes in organic and inorganic phosphorus composition of two grassland soils and their particle size fractions during 60-90 years of cultivation. J. Soil Sci. 34:815-823.

Walker, T.W., and A.F.R. Adams. 1958. Studies on soil organic matter: I. Influence of phosphorus content of parent materials on accumulations of carbon, nitrogen, sulfur and organic phosphorus in grassland soils. Soil Sci. 85:307-318.

Williams, J.D.H., and T.W. Walker. 1967. Comparison of ignition and extraction methods for the determination of organic phosphorus in rocks and soils. Plant Soil 27:457-458.

Williams, J.D.H., J.K. Syers, T.W. Walker, and R.W. Rex. 1970. A comparison of methods for the determination of soil organic phosphorus. Soil Sci. 110:13-18. 